\title{
Appraisal of gut lavage in the study of intestinal humoral immunity
}

\author{
S O’Mahony, J R Barton, S Crichton, A Ferguson
}

\begin{abstract}
Direct investigation of intestinal humoral immunity requires collection of intestinal secretions or mucosal biopsy specimens, or both. A non-invasive technique of gut lavage, with a polyethyleneglycol electrolyte lavage solution as a means of collecting intestinal secretions for immunoglobulin and antibody studies, was evaluated. Fifty patients were studied - 25 immunologically normal patients or volunteers, 15 patients with untreated coeliac disease, and 10 patients with active Crohn's disease. Protease inhibitors were added promptly to samples to prevent proteolysis of immunoglobulin content. Treated lavage samples were assayed by enzyme linked immunosorbent assay for immunoglobulin and antibody content. Studies of serial lavage specimens showed that early, faecally contaminated specimens contained negligible quantities of immunoglobulin, but once the specimens became clear a steady state was reached, with little variation in immunoglobulin content between serial specimens and with a uniform dilution (around 20\%) of the ingested polyethyleneglycol. Gut lavage fluid IgA was predominantly secretory, comprising $92 \%, 81.6 \%$, and $76.7 \%$ respectively of the total IgA gut lavage fluid content in the control, coeliac, and Crohn's groups. High values of total IgM and IgA and IgM antigliadin antibodies were detected in the coeliac group, and high values of IgG in the Crohn's disease group. This method of gut lavage is not only an effective bowel cleanser, but also a noninvasive means of obtaining intestinal secretions for the study of humoral immunity in gastrointestinal disease.
\end{abstract}

The mucosal immune system is largely independent of the systemic immune system. Therefore, for investigation of local immunity in gastrointestinal disease, the gut must be studied directly. Human research in this area has been hampered by difficulty of access to intestinal secretions. Gaspari and colleagues recently described a non-invasive gut lavage and sample processing technique that they performed in 12 healthy volunteers. ${ }^{1}$ Human intestinal secretions contain large amounts of proteases, ${ }^{23}$ and they found that loss of immunoglobulin content due to proteolysis could be prevented by treating specimens with protease inhibitors. We have further evaluated this technique, studying immunoglobulin content and specific antibody (antigliadin) activity in both healthy subjects and patients with gastrointestinal conditions (coeliac disease and Crohn's disease) where aberrant immune regulation is thought to play a pathogenic role.

\section{Subjects and methods}

\section{SUBJECTS}

Gut lavage was performed in 50 subjects. Twenty five were immunologically normal patients (16 women, nine men, median age 52 , range 21-92 years) who underwent lavage as a bowel preparation for barium enema or colonoscopy, or who volunteered when invited. (No organic pathology was found in these patients, and final diagnosis in most was functional bowel disorder.) Fifteen subjects were patients with untreated coeliac disease (nine women, six men, median age 43, range 28-62 years), all of whom had had a recent jejunal biopsy specimen showing subtotal or severe partial villous atrophy. Ten patients with active Crohn's disease were also studied (four women, six men, median age 27 , range $18-92$ years).

\section{LAVAGE SOLUTION}

The lavage solution is a polyethyleneglycol electrolyte lavage solution. This is available commercially in the USA (Golytely) and is widely used as a method of cleansing the colon for barium enema and colonoscopy. ${ }^{4}$ The lavage solution was formulated by the hospital pharmacy and contained $59.1 \mathrm{~g}$ polyethyleneglycol 3350 (a mixture of different sized molecules with a mean molecular weight between 3200 and 3700), potassium chloride BP $0.75 \mathrm{~g}$, sodium chloride BP $1.45 \mathrm{~g}$, sodium bicarbonate BP $1.63 \mathrm{~g}$, and sodium bisulphate BP $5.68 \mathrm{~g}$, made up to 1 litre with a resultant osmolality of $260 \mathrm{mOsm} / 1$.

\section{LAVAGE PROTOCOL}

After an overnight fast, lavage was begun at 830 am. Patients were asked to drink the lavage solution at a rate of $250 \mathrm{ml}$ every 15 minutes for a period of four hours, making the total volume consumed 4 litres. The solution was found to be more palatable if consumed chilled and flavoured with a little lemon juice. In patients in whom 
lavage was used as a bowel preparation, one sachet of sodium picosulphate (Picolax) was given later in the afternoon of the same day.

\section{SPECIMEN PROCESSING}

Stool collection was begun once the material passed per rectum became liquid, clear, and free of faecal material. Approximately $200 \mathrm{ml}$ were collected and filtered into $50 \mathrm{ml}$ polypropylene tubes. Specimens were centrifuged twice and treated with protease inhibitors as described by Gaspari et al. ${ }^{1}$ Treated samples were aliquoted and stored at $-70^{\circ} \mathrm{C}$. In four subjects, early faecal specimens were collected and processed along with later clear specimens. In 10 subjects, the first clear specimen was divided into three aliquots - one was treated immediately, but treatment was delayed for one and two hours each in the other two to determine the time course of sample deterioration due to proteolysis. In 14 subjects, two serial clear specimens were collected to determine whether immunoglobulin content varied between specimens.

ENZYME LINKED IMMUNOSORBENT ASSAY (ELISA) Total IgA, IgM, and IgG; secretory IgA. Assays were performed in 96 well microtitre ELISA plates (Dynatech). All reactants were added in volumes of $0 \cdot 125 \mathrm{ml}$ per well and all washes were done three times using saline with $0.05 \%$ Tween 80 added. For the assay of total $\operatorname{IgA}$, wells were coated with $100 \mathrm{ng} / \mathrm{ml}$ affinity purified goat antihuman IgA (Northeast Labs) in $0.1 \mathrm{M}$ carbonate buffer, $\mathrm{pH} \mathbf{9 \cdot 6}$, and were incubated overnight at $4^{\circ} \mathrm{C}$ and washed. After washing, serial twofold dilutions ranging from 1250-19.35 $\mathrm{ng} / \mathrm{ml}$ of a human colostral IgA standard (Sigma) and serial dilutions of treated lavage samples (initial dilution 1/100) were added to the coated wells. Plates were incubated overnight at $4^{\circ} \mathrm{C}$ and washed. Goat antihuman IgA conjugated with alkaline phosphatase (Northeast Labs) diluted (in saline with $1 \%$ fetal calf serum and $0.05 \%$ Tween 80) to a predetermined optimal level was added and plates were incubated for three hours at $20^{\circ} \mathrm{C}$. After washing, paranitrophenylphosphate (PNPP, Sigma) $1 \mathrm{mg} / \mathrm{ml}$ in $10 \%$

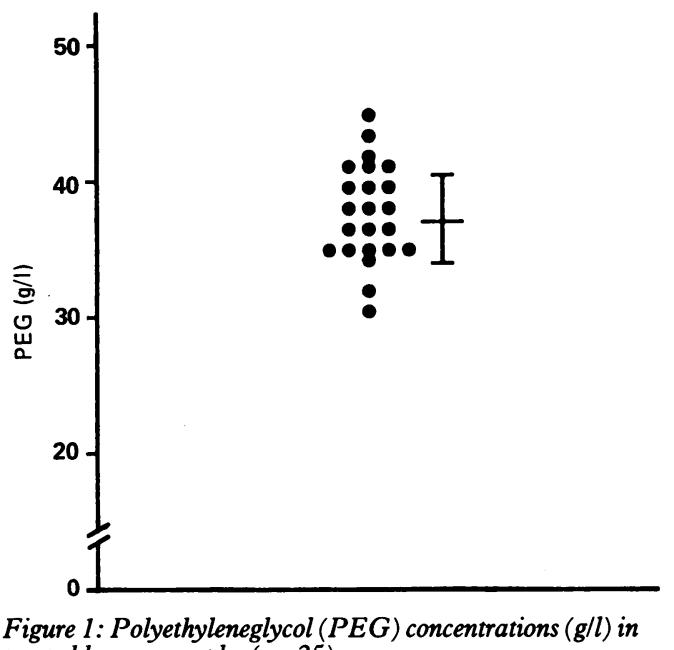
Figure 1: Polyethyleneglycol $(P E$
treated lavage samples $(n=25)$. diethanolamine (DEA) buffer, $\mathrm{pH}$ 9.8, was added. Plates were read at an optical density of 405 in an MR580 microELISA reader (Dynatech). A standard curve was constructed; the IgA content of any given sample was determined by taking the mean IgA content of those two sample dilutions whose optical density fell within the range of the standard curve. The method used to determine total IgM and IgG was similar; human reference serum (Protein Reference Unit, Sheffield) was used as a standard, and the initial sample dilution was $1 / 25$.

The assay for secretory $\operatorname{Ig} A^{6}$ was similar to that for total $\operatorname{IgA}$; wells were coated with a goat antihuman secretory piece (Atlantic Antibodies), the same human colostral IgA was used as a standard.

Antigliadin antibodies. The assay was similar to that described above. Wells were coated with crude gliadin at a concentration of $5 \mu \mathrm{g} / \mathrm{ml}$. Serum from a patient with untreated coeliac disease was used as a positive standard, and lavage samples were added in duplicate dilutions of $1 / 2$ (this dilution gave optimal optical density readings). Plates were read when the standard reached an arbitrary optical density of $1 \cdot 0$; antibody levels are given in the form of optical density readings expressed as percentages of the optical density of the standard.

\section{MEASUREMENT OF POLYETHYLENEGLYCOL}

VALUES IN LAVAGE SAMPLES

Polyethyleneglycol was quantified by the method of Malawer and Powell, ${ }^{7}$ a modification of the turbidimetric analysis of Hyden.

\section{STATISTICAL ANALYSIS}

Differences in IgA content of serial lavage specimens were analysed with the paired $t$ test. Differences in immunoglobulin and antibody values between patient groups were analysed with the Mann-Whitney U test.

\section{Results}

\section{POLYETHYLENEGLYCOL CONCENTRATIONS IN} TREATED SAMPLES

Mean (SD) polyethyleneglycol concentration in the processed samples of 25 subjects was $37 \cdot 3$ (3.4) $\mathrm{g} / \mathrm{l}$. The initial concentration of $59.1 \mathrm{~g} / \mathrm{l}$ in the ingested lavage fluid would be reduced to $47.5 \mathrm{~g} / 1$ by the addition of protease inhibitors, etc; thus, the liquid stools were comprised on average of $78.5 \%$ polyethyleneglycol lavage solution and $21.5 \%$ gastrointestinal secretions. There was little variation about the mean (Fig 1).

\section{IMMUNOGLOBULIN CONTENT IN SERIAL} SPECIMENS

Early faecally contaminated specimens contained low concentrations of IgA compared with later clear specimens (Table I). Once the specimens became clear, there was no significant difference in IgA content between serial specimens (Fig 2). 


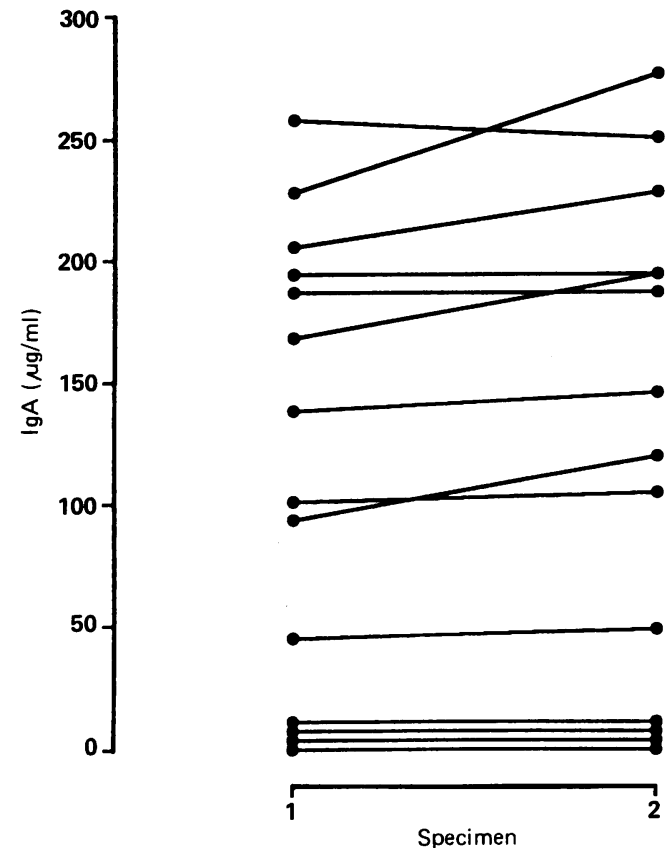

Figure 2: IgA concentrations $(\mu \mathrm{g} / \mathrm{ml})$ in serial lavage specimens $(n=14)$

PROTEASE INHIBITION

Delays of one and two hours in the addition of protease inhibitors resulted in loss of IgA content varying from 0 to $92 \%$ (Fig 3 ).

IMMUNOGLOBULIN AND ANTIBODY VALUES IN THE PATIENT GROUPS

Mean immunoglobulin values are shown in Table II. No significant difference in IgA values was found between the three groups. High IgM values were found in the coeliac group $(p<0.02 v$ control subjects) and in the Crohn's patients ( $<<0.05 v$ control subjects), with no significant difference between the coeliac and Crohn's groups. High IgG values were found in the Crohn's patients $(\mathrm{p}<0.00001 v$ control subjects; $\mathrm{p}<0.0005 v$ coeliac group).

Antigliadin antibody values are shown in Figure 4. High IgA antigliadin antibody values were found in the coeliac patients $(p<0.002 v$ control subjects, $\mathrm{p}<0.01 v$ Crohn's patients), with similar values in control subjects and Crohn's patients. High IgM antigliadin antibody values were also found in the coeliac patients

TABLE I IgA concentration $(\mu g / m l)$ in early faecal specimen compared with clear lavage specimens

\begin{tabular}{lll}
\hline Patient & Early specimen & Clear specimen \\
\hline 1 & 3.3 & 16.3 \\
2 & $<2.0$ & 83.6 \\
3 & 3.8 & $18 \cdot 1$ \\
4 & $<2.0$ & 91.4 \\
\hline
\end{tabular}

TABLE II Lavage fluid immunoglobulin concentrations (mean $(S E)$ ) in $\mu g / m l$

\begin{tabular}{llcc}
\hline Group & $I g A$ & $I g M$ & $I g G$ \\
\hline Control $(\mathrm{n}=25)$ & $136.9(20 \cdot 6)$ & $9 \cdot 26(2 \cdot 02)$ & $2 \cdot 38(0 \cdot 72)$ \\
Coeliac $(\mathrm{n}=15)$ & $173 \cdot 6(33 \cdot 8)$ & $23 \cdot 66(6 \cdot 69)^{\star}$ & $5 \cdot 57(2 \cdot 42)$ \\
Crohn's $(\mathrm{n}=10)$ & $176 \cdot 1(58 \cdot 0)$ & $17 \cdot 82(4 \cdot 5)^{\star}$ & $28.93(6.75)^{\star}$ \\
\hline
\end{tabular}

*Values significantly higher $(\mathrm{p}<0.05)$ compared with controls.

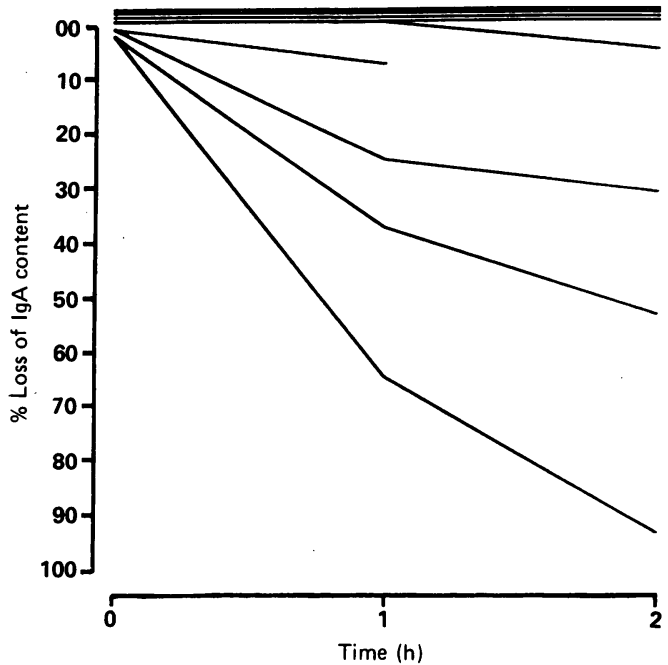

Figure 3: Effect of delay in addition of protease inhibitors on lavage fluid IgA content.

$(\mathrm{p}<0.0002 v$ control subjects, $\mathrm{p}<0.02 v$ Crohn's patients), with similar values in control subjects and Crohn's patients.

\section{SECRETORY IgA CONTENT}

The mean (range) percentage of lavage fluid total IgA expressing secretory component was as follows: control subjects: $92 \cdot 0 \%(82 \cdot 3-100 \cdot 0)$; coeliac patients: $81 \cdot 6 \%(57 \cdot 8-98 \cdot 7)$; and Crohn's patients: $76 \cdot 7 \%(64 \cdot 0-91 \cdot 3)$.

\section{Discussion}

Investigation of intestinal humoral immunity presents major logistic problems. Some investigators have extrapolated information from studies of peripheral blood and saliva as representative of immune events in the gut. Although this approach may be valid in certain instances for example, in the study of IgA secreting B cells after enteral infection or immunisation ${ }^{9}$ - for definitive studies of intestinal immunity, the gut must be studied directly. For example, we have found no correlation between systemic and mucosal (salivary and jejunal aspirate) antibodies in coeliac disease (unpublished observations).

The gut lavage method described is safe, noninvasive, and useful for bowel cleansing and treatment of constipation. ${ }^{10}$ The technique is well tolerated by most patients. We have now carried out gut lavage in over 100 subjects, and the procedure was abandoned in only two patients, who were unable to consume the volume of liquid required. Polyethyleneglycol electrolyte lavage solutions are not absorbed and have minimal effects on fluid and electrolyte balance. ${ }^{112}$ Other investigators have used saline lavage for collection of intestinal secretions, ${ }^{13}$ but this is contraindicated in patients with cardiac, renal, and hepatic disease.

Processing of specimens is crucial to success in subsequent laboratory assays. Several studies have shown that human intestinal secretions contain large amounts of protease,${ }^{14}$ and that the addition of protease inhibitors prevents appreciable immunoglobulin loss ${ }^{1}$ and improves antigen stability for ELISA. ${ }^{3}$ We and others ${ }^{1}$ have shown 


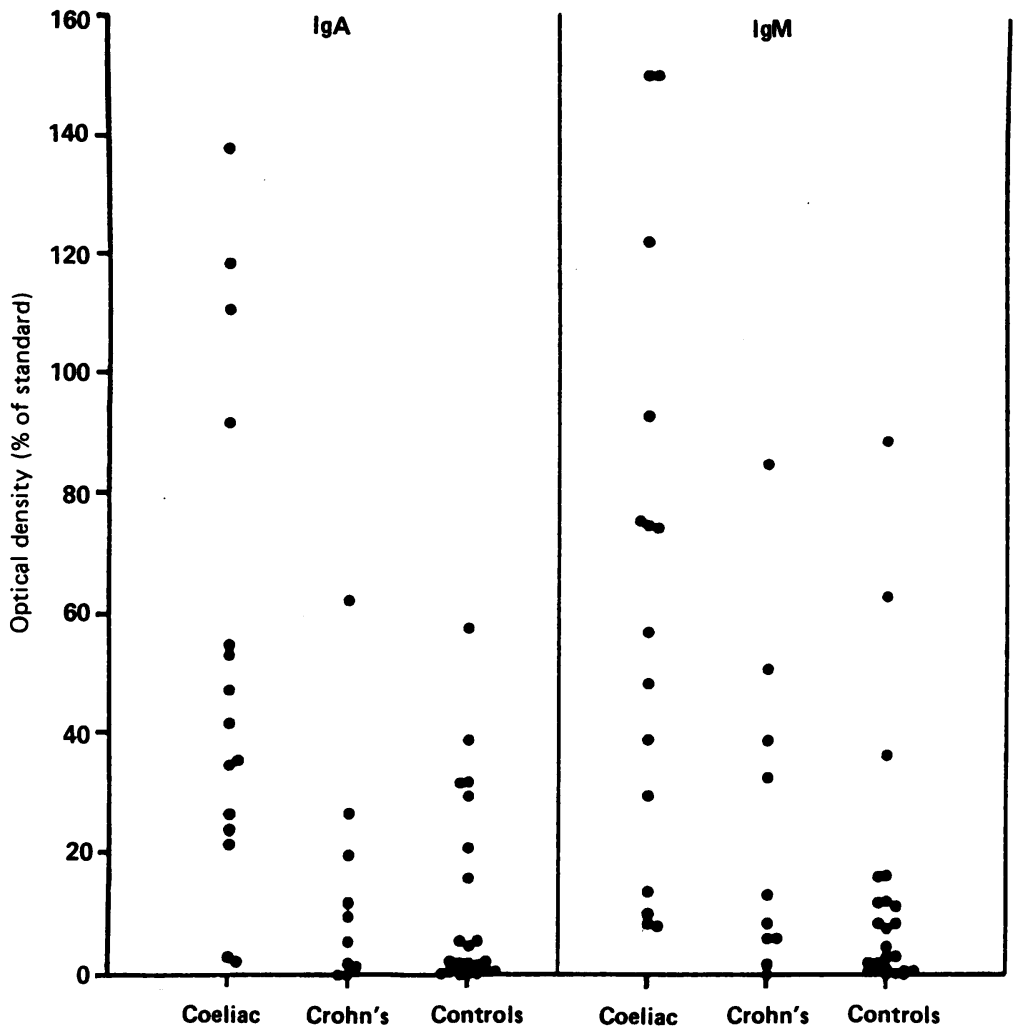

Figure 4: Lavage fluid IgA and IgM antigliadin antibody values.

that delay in addition of protease inhibitors to secretions obtained by this method may result in significant loss of immunoglobulin content.

Results of total IgA content of serial specimens indicates that once the patient passes clear fluid per rectum, a steady state is reached, with no difference in immunoglobulin content between subsequent specimens. Analysis of semiliquid early faecal specimens, however, showed negligible quantities of $\operatorname{IgA}$ compared with that found in clear specimens. This must cast doubt on attempts to assess mucosal immunity by studies on faeces.

These preliminary studies on patients with coeliac disease and Crohn's disease have shown substantial qualitative differences between patient groups in patterns of isotype specific immunoglobulins, and these findings are being confirmed in continuing definitive investigations. Specific antibodies can also be readily measured, as we have shown with gliadin and others have shown with cholera toxin B subunit.'

It could be argued that increased intestinal permeability in patients with coeliac disease and Crohn's disease may allow serum leakage of immunoglobulin and antibody into the gut lumen. It is quite possible that at least some lavage fluid immunoglobulin is serum derived, but we have shown that lavage fluid IgA is predominantly secretory in the three patient groups.

The finding of high values of lavage fluid IgG in the Crohn's group could reflect altered intestinal immunoglobulin production in this condition; ${ }^{15}$ however, as there is no specific mucosal transport system for IgG, it is more likely that the IgG is serum derived, leaking across the inflamed mucosa.

This technique has great potential for in vivo determination of immunoglobulins and antibody in the gut, and can be applied to a wide range of studies of secretory immunity in health and disease.

We thank Doctors M Gaspari and C O Elson for details of specimen processing. Mrs J Johnstone and $\mathrm{Mr} \mathrm{N}$ Anderson provided technical assistance. Dr O'Mahony is funded by Fison Pharmaceuticals.

This work was presented at the British Society of Gastroenterology Autumn meeting, Dublin, September 1989.

1 Gaspari MM, Brennan PT, Solomon SM, Elson CO. A method of obtaining, processing, and analyzing human intestinal secretions for antibody content. F Immunol Methods 1988 ; 110: 85-91.

2 Samson RR, McClelland DBL, Shearman DJC. Studies on the quantitation of immunoglobulin in human intestinal secre tions. Gut 1973; 14: 616-26.

3 Hohmann A, Labrooy J, Davidson GP, Shearman DJC Measurement of specific antibody in human intestinal aspirate: effect of the protease inhibitor phenylmethyl sulphonyl fluoride. F Immunol Methods 1983; 64: 199-204.

4 DiPalma JA, Brady CE, Stewart DL, et al. Comparison of colon cleansing methods in preparation for colonoscopy. Gastroenterology 1984; 86: 856-60.

5 Soergal KH, Hogan WJ. On the suitability of poorly absorbed markers as dilution indicators in the gastrointestinal tract. Gastroenterology 1967; 53: 1056-7.

6 Wood GM, Trejdosiewicz LK, Losowsky MS. ELISA for measurement of secretory IgA distinct from monomeric measurement of secretory IgA distinct

7 Malawer SJ, Powell DW. An improved turbidimetric analysis of polyethylene glycol using an emulsifier. Gastroenterology 1967; 53: 250-6

8 Hyden S. A turbidimetric method for determination of highe polyethylene glycols in biological materials. Ann R Agric Coll Sweden 1955; 22: 139-45.

9 Forrest BD. Identification of an intestinal immune response using peripheral blood lymphocytes. Lancet 1988; i: 81-3.

10 Puxty JA, Fox RA. Golytely: a new approach to faeca impaction in old age. Age Ageing 1986; 15: $182-4$

11 Davis GR, Santa Ana CA, Morawski SG, Fordtran JS Development of a lavage solution associated with minimal water and electrolyte absorption or secretion. Gastroenterwater and electrolyte

12 DiPiro JT, Michael KA, Clark BA, et al. Absorption of polyethylene glycol after administration of a PEG-electrolyte polyethylene glycol after administration of a
lavage solution. Clin Pharm 1986; 5: 153-5.

13 Svennerholm A-M, Sack DA, Holmgren J, Bardhan PK. Intestinal antibody responses after immunization with cholera B subunit. Lancet 1982; i: 305-8.

14 Brown WR, Newcombe RW, Ishizaka K. Proteolytic degradation of exocrine and serum immunoglobulins. 7 Clin Inves 1970; 49: 1374-80.

15 MacDermott RP, Nash GS, Bertovich MJ, et al. Alterations of gM, IgG and Ig A synthesis and secretion by peripheral lood and intestinal mon blood and intesunal mononuclear cells from patients with 81: 844-52. 